العـــــــد الثالث والثلاثون

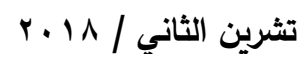

مجلــــة كليـــــة التربيــــة

\title{
مخاطر الجريان السيلي في أودية شرقي محافظة ميسان
}

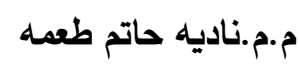

أ.م.د. طلال مريوش جاري

\section{جامعة واسط / كلية التربية}

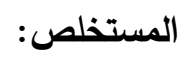

شملت هذه الدراسة احواض الاودية الجافة شرقي محافظة ميسان الممتدة على طول الحدود

العراقية الايرانية ومنابعها في ايران او القرببة منها والبالغ عددها (ع ()) حوضاً. أعتمدت الدراسة على مده معادلة بيركلي لتقدير حجم الجريان السطحي في احواض المنطقة ونتائج معادلات نموذج سنايدر الاحصائي لدراسة خصائص الاحواض الهيدرولوجية وهي زمن التركيز والتباطؤ وزمن الاساس وسرعة الجريان ومدة الارتفاع والانخفاض التدرجي وقيمة التدفق الاقصى وقوة مياه السيل والمدة المثالية لسقوط الامطار ، كما تم استعمال الجداول والخرائط لتسهيل المقارنة واستخلاص النتائج •

توصلت الدراسة الى تصنيف الاحواض الى متوسطة الخطورة شملت ست أحواض وهي (حوض قره تبه، وحوض الفكة، وحوض الاخيصر ، وحوض أبو غرببات، وحوض الحليوات، وحوض السلمانة). وأحواض عالية الخطورة شملت ثمانية احواض موزعة بين شمال وجنوب وشرق منطقة الدراسة وهي (حوض الزعفران، وحوض الجفته (ناشريان)، وحوض جلات، وحوض الشرهاني، وحوض الثكالك، وحوض العيلة، وحوض المغيسل، وحوض الاعمى).

\section{Abstract:}

The study included dry Valleys in the eastern province of Maysan along the Iraqi-Iranian border and its sources in Iran or nearby (14) basin. The study was based on the Berkeley equation for estimating the volume of surface runoff in the area ponds and the results of the Snyder model statistical 
العـــــــد الثالث وإلثلاثون

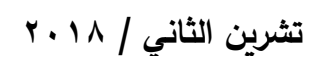

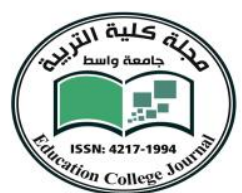

equations for the study of the properties of the hydrological basins, the time of concentration and deceleration, the base time, the flow velocity, the duration of the rise and the gradual decrease, the maximum flow value, the strength of the water, the ideal duration of rainfall, Comparing and extracting results.

The study identified the classification of the ponds to medium risk, which includes six basins (Kara Tabbah Basin, Al Fakkah Basin, Al Ahkaysar Basin, Abu Ghraibat Basin, Halawat Basin and Salmana Basin). The basin consists of eight basins distributed between the north, south and east of the study area (Saffron basin, Jaffet basin, Gillat basin, Al Sharhani basin, Shakak basin, Al Eila basin, Mughisil basin and Umma basin).

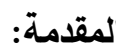

تعمل الادوية الجافة والأنهار الموسمية التي يكون القسم الاكبر منها في الاراضي الايرانية على جلب كميات كبيرة من السيول الجارفة في المواسم المطيرة من الاراضي الايرانية الى منطقة الدراسة، بعضها يصب في هور السناف ثم اهوار الحويزة الثرقية، كما في نهر دويريج والطيب اللذان

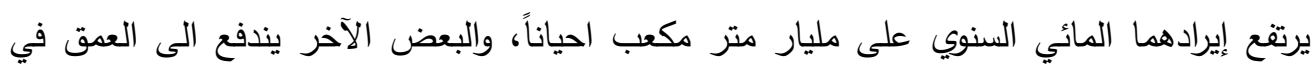

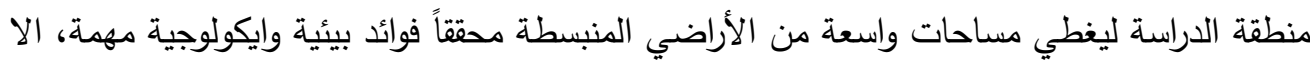
انه في بعض الأحيان يسبب إضراراً كبيرة في الممتلكات والمزارع والإحياء والقرى المنتشرة في منطقة الدراسة. إذ تعد السيول Flash Floods من أسوء واخطر الشاكل البيئية والمخاطر الطبيعية المرتبطة بتكرار سقوط الأمطار الثديدة في الاقاليم الجافة وشبه الجافة ومنها منطقة الدراسة. تعرف

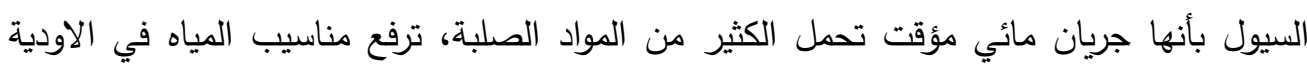
والمجاري المائية، تظهر بشكل مفاجى، لايمكن التتبؤ بموعد ظهورها في اليوم أو الساعة، تتميز بسرعة الجريان ثم تتاقصه السريع كماً وسرعة. 
العـــــــد الثالث والثلاثون

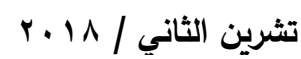

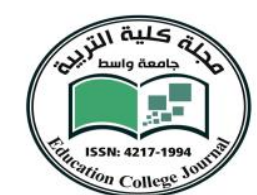

أما الأحواض المائية فتعرف بأنها وحدة جيومورفولوجية تعمل على تجمع مياه الأمطار

الساقطة عليها وتصريفها بشكل تيارات من خلال نقطة مشتركة. تمتلك منطقة الدراسة شبكة كبيرة من أحواض التصريف المائي ويرجع ذلك الى عوامل اساسية أهمها الظروف المناخية السائدة، إذ تستقبل المنطقة كمية كبيرة نسبياً من مياه الأمطار مما جعل أودية المنطقة تتميز بغناها الواضح في مواردها

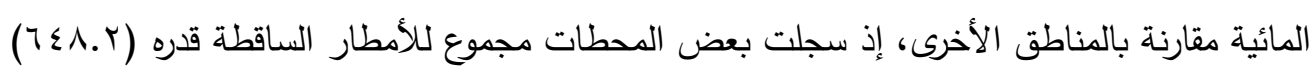
ملم في محطة دهلران عام 999 1 تركزت في اشهر كانون الثاني وشباط واذار ونيسان، كما سجلت محطة العمارة مجموع مطري قدره (Y.r.r) ملم عام 1999 خلال الاشهر كانون الاول وكانون

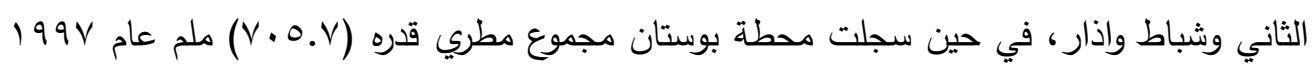
خلال اشهر تشرين الثاني وكانون الثاني واذار(')، مما يدل على ارتفاع مجاميع الامطار المتساقطة في منطقة الدراسة والمناطق المجاورة لها من الجهة الثرقية في ايران. فضلاً عن طبيعة الانحدار الثديد لمرتفعات تلك المنطقة مما ترك الاثر الواضح لتعدد الاحواض التصريفية وزيادة كثافتها، وبالرغم من نشاط الحت الرأسي وعمليات التعرية الأخرى ووفرة المياه لكنها لم تأسر بعضها و بقيت على شكل مجموعات متوازية ومتقاربة من بعضها، كما تشترك تلك الاحواض في بعض الخصائص من اهمها تجانس التكوينات الجيولوجية والصخرية الممتدة عبرها الاحواض التصريفية، مما عمل على ازدياد المجاري والروافد على اختلاف رتبها النهرية وذلك نتيجة غنى المنطقة بالثقوق والفواصل التي تعمل كمسارات عند تجمع مياه الأمطار فيتكون عدد كبير من الروافد تتجمع فيها كميات كبيرة من المياه التي تزيد من احتمالية حدوث السيول عند وصولها إلى المجرى.

اعطى النظام البيئي الفيضي في منطقة الدراسة أهمية مكانية وبيئية كبيرة لها كون بطون الأودية ومنحدراتها تتميز بعوامل جغرافية تشجع الاستثارات البشرية حيث المراعي الجيدة وتوفر المياه الجوفية المخزونة الصالحة للاستخدام البشري طيلة ايام السنة، مما يعرضها لمخاطر الانجراف والتدمير بسبب الجريان السيلي الفيضي. 


\section{العـــــــدد الثالث والثلاثون}

مشكلة الدراسة: تمحورت حول مجموعة اسئلة تدور في ذهن الباحث وهي:

هل توجد مخاطر للجريان السيلي في تلك الاودية؟

ماتصنيف درجة خطورة تلك المخاطر؟

فرضية الدراسة: وهي اجابة اولية على تساؤلات ومشاكل الدراسة ويمكن ان تصاغ كالاتي:

توجد مخاطر للجريان السيلي في الاودية الددروسة. تصنف درجات الخطورة الى مستويات عدة.

منطقة الدراسة:

تتاولت الدراسة الاحواض الواقعة شرقي محافظة ميسان التي منابعها في ايران او القريبة

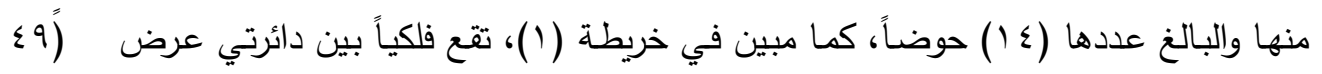
أ

تعد خصائص الاحواض الهيدرولوجية في منطقة الدراسة انعكاساً للظروف الهناخية ولطوبغرافية الاحواض ذات الاهمية الكبيرة في توضيح مدى تأثير تصريف تلك الاحواض على لقدئ

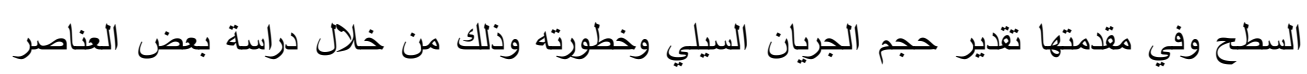
للاحواض في منطقة الدراسة. 


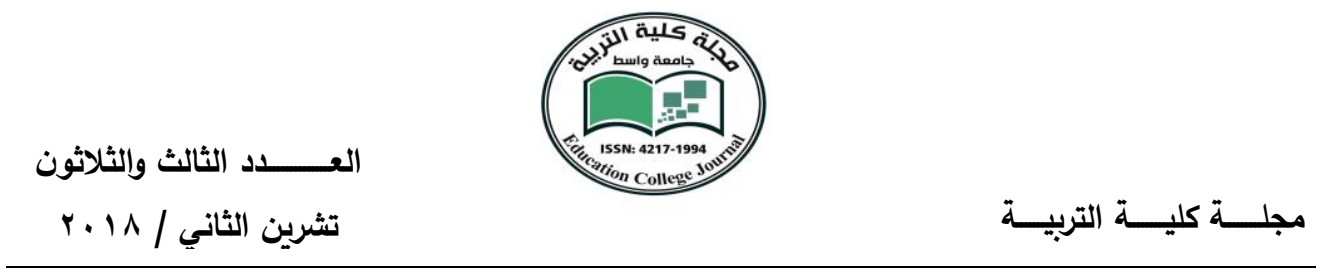

خريطة (1)

الاحواض في منطقة الدراسة

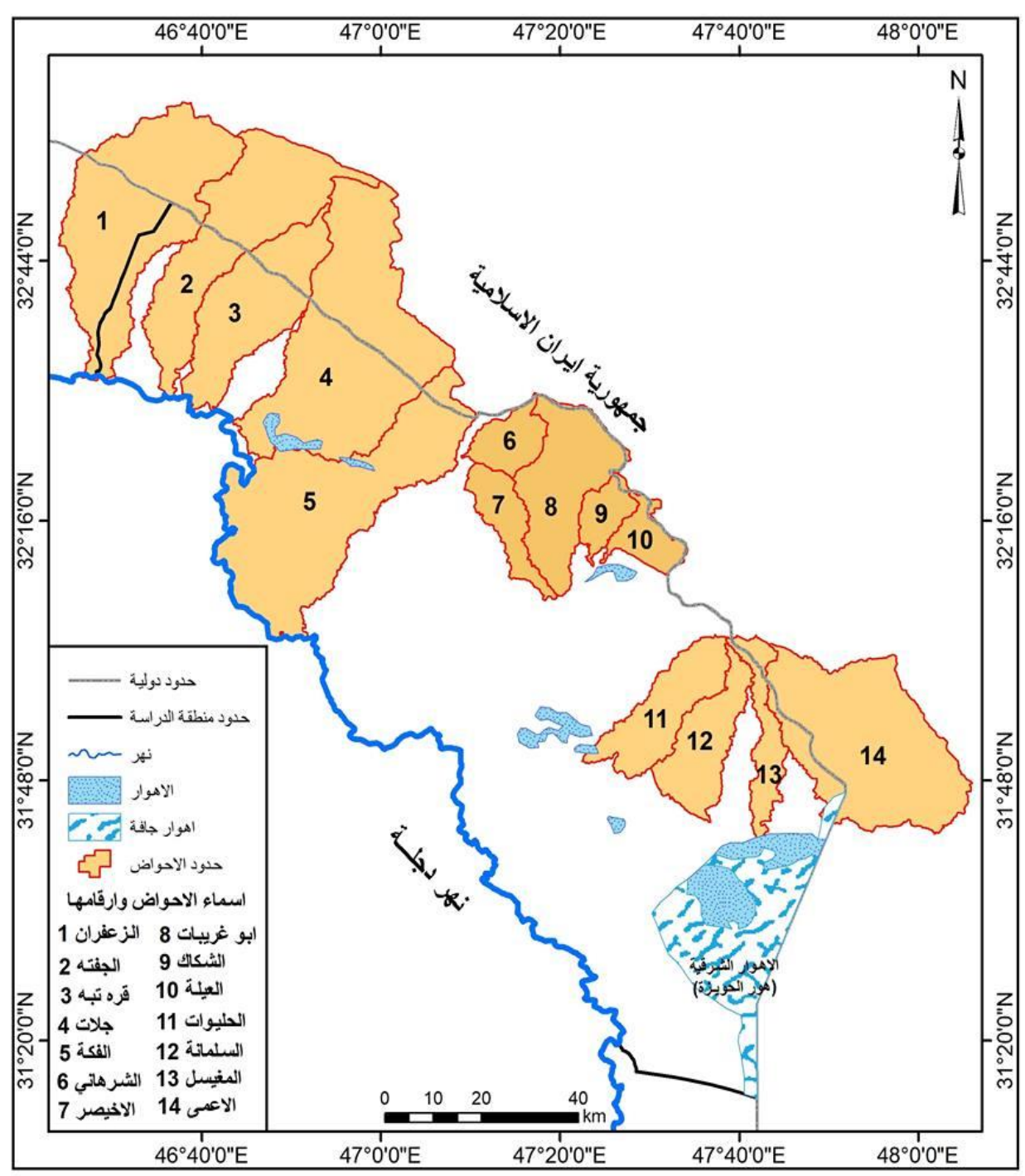

المصدر :الباحثة بالاعتماد على الخريطة الطوبوغرافية لمحافظة ميسان بو 19 مقياس . . . . . 1:1 وباستخدام Arc Map 10.4 برنامج 
العـــــــد الثالث والثلاثون

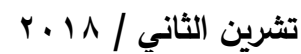

مجلــــة كليــــة التربيــــة

اولاً: تقدير حجم الجربيان السطحي

تم استخدام طريقة بيركلي التي تعتمد على عنصري المناخ والتضاريس لتقدير حجم الجريان السطحي وذلك بالاعتماد على بيانات المحطات المناخية الخاضعة للدراسة وهي (العمارة، البصرة

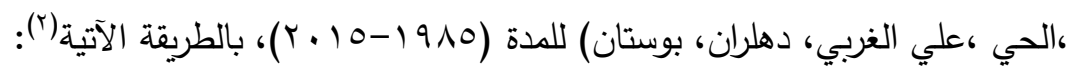
$R=(C I S)^{1 / 2}(W / L)^{0.45}$

إذ أن

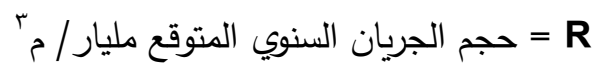
I = = حجم الجريان السنوي المتوقع مليار / م م (يحسب بضرب معدل المطر السنوي/ ملم في مساحة الحوض ومن ثم تقسيم الناتج على . . . . . . 1 ) = S = W = L ق قيمة ثابتة في المناطق الجافة وشبه الجافة . C C

يظهر من جدول (1) تباين حجم الجريان السنوي المتوقع في احواض منطقة الدراسة وذلك يعتمد على كمية الأمطار الساقطة على الأحواض التي تغطيها محطات الدراسة، كذلك تباين مساحة الاحواض ومعدل عرضها ومعدل انحدارها، فترتبط تلك الخصائص بعلاقة طردية مع حجم الجريان السطحي ممايزيد من خطورة الاحواض. كما تراوح حجم الجريان السطحي في تلك الاحواض بين

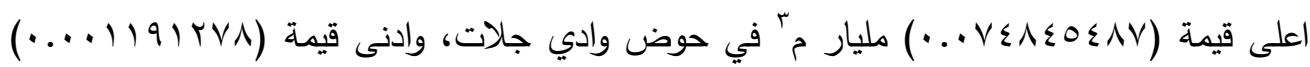
مليار مَّفي حوض المغيسل. إذ يترتب على تباين حجم الجريان السطحي تباين خطورة الاحواض و معدلات التعرية في احواض المنطقة. 
العـــــــد الثالث والثلاثون

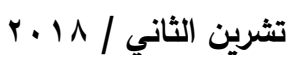

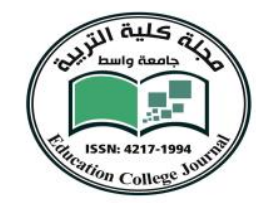

مجلــــة كليــــة التربيــــة

ثانياً: الخصائص الهيدرولوجية الاخرى

تم الاعتماد على نموذج سنايدر لاستخراجها فهي كالاتي:-

1- زمن التركيز Time of Concentration

هو الوقت اللازم لتحرك المياه في حوض التصريف من أقصى نقطة إلى نقطة المصب،

ووصوله إلى أعلى مستوى لله مع الثبات على مستوى التصريف مهما طالت مدة العاصفة المطرية،

وعنده يكون معدل الجريان السطحي مساوياً لاي زيادة في التساقط.تساعد معادلة زمن مئن

جدول (1)

حجم الجريان السطحي وبعض المتغيرات الهيدرولوجية في احواض منطقة الاراسة

\begin{tabular}{|c|c|c|c|c|c|c|c|c|c|c|c|c|c|c|c|c|}
\hline 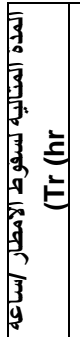 & 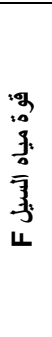 & 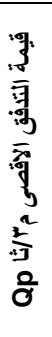 & 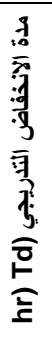 & 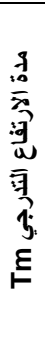 & 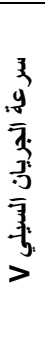 & 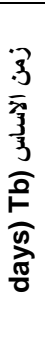 & 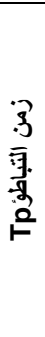 & 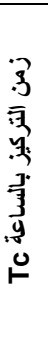 & 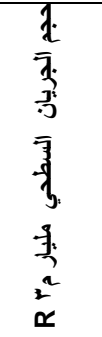 & $\begin{array}{l}3 \\
3 \\
3 \\
3 \\
9 \\
3 \\
\overline{3} \\
3 \\
3\end{array}$ & 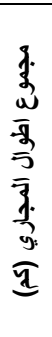 & 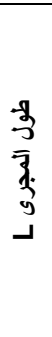 & 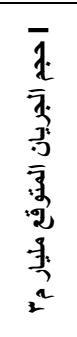 & $\begin{array}{l}\frac{3}{3} \\
\frac{3}{3} \\
y \\
\frac{1}{2} \\
\frac{3}{2} \\
\frac{2}{2}\end{array}$ & ضا ضو & ت \\
\hline$\ddot{q}$ & 11 & $\begin{array}{l}r / 1 \\
\square . V\end{array}$ & $\begin{array}{l}7 . \\
.9\end{array}$ & . & $\begin{array}{l}11 \\
. v\end{array}$ & r. & $\begin{array}{l}Y . \\
\vdots\end{array}$ & ? & & $\begin{array}{l}1 \leqslant \\
.9\end{array}$ & $\begin{array}{l}4 \\
0.4\end{array}$ & $\begin{array}{l}.0 V \\
. r\end{array}$ & $\begin{array}{l}-I Y{ }^{\prime} \\
\text { TVY }\end{array}$ & 1 & |الزعفر| & 1 \\
\hline$\ddot{0}$ & $\begin{array}{l}r \mu \\
. r\end{array}$ & $\begin{array}{l}\text { Vo } \\
\text { A. }\end{array}$ & $\begin{array}{l}r . \\
. \wedge\end{array}$ & $\begin{array}{l}\mu . \\
.\end{array}$ & . & $r$. & r. & 0. & v४srq & $\begin{array}{l}11 \\
0\end{array}$ & $\begin{array}{l}99 \\
\because 1\end{array}$ & $\begin{array}{l}00 \\
. \varepsilon\end{array}$ & $\begin{array}{l}\because \cdot 9 . \\
r \leqslant 1\end{array}$ & די & (ناشيرا & $r$ \\
\hline$i$ & $\varepsilon$ & $\begin{array}{l}\qquad \wedge . \\
q\end{array}$ & $\begin{array}{l}7 . \\
. \wedge\end{array}$ & $\begin{array}{l}r . \\
.\end{array}$ & $\theta$. & r. & i. & $\frac{9}{9}$ & $\begin{array}{l}\because \cdots 94 \\
r i 94 \pi\end{array}$ & q. & $\begin{array}{l}\text { VI } \\
r . r\end{array}$ & $\begin{array}{l}\xi v \\
. v\end{array}$ & $\begin{array}{l}\because 90 \\
\text { rra }\end{array}$ & $\begin{array}{l}54 \\
r\end{array}$ & قره تبه & $r$ \\
\hline$\because$ & $\begin{array}{l}\text { IV } \\
.4\end{array}$ & $\begin{array}{l}4 \pi \\
\Lambda .7\end{array}$ & $\begin{array}{l}.9 q \\
. r\end{array}$ & $\begin{array}{l}49 \\
.9\end{array}$ & $\wedge$ & r. & r. & ร. & $\begin{array}{l}\because \cdot V \leqslant \Lambda \\
\leqslant 0 \leqslant \wedge \vee\end{array}$ & $\begin{array}{l}19 \\
.0\end{array}$ & $\begin{array}{l}19 \\
0 .\end{array}$ & $\begin{array}{l}0 \leqslant \\
.\end{array}$ & $\begin{array}{l}\because 1 \leqslant 9 \\
109\end{array}$ & 10 & جلات & $\varepsilon$ \\
\hline$\dot{r}$ & 9 i & $\begin{array}{l}r . \\
0.1\end{array}$ & $\begin{array}{l}. V V \\
. V\end{array}$ & $\begin{array}{l}r \wedge \\
. \wedge\end{array}$ & ๕. & $\begin{array}{l}r . \\
i\end{array}$ & $\begin{array}{l}7 . \\
0\end{array}$ & I & $\begin{array}{l}\because+14 r \\
r 00.0 .\end{array}$ & $\begin{array}{l}10 \\
.9\end{array}$ & F & $\begin{array}{l}74 \\
.4\end{array}$ & $\begin{array}{l}-1 \leqslant 1 \\
\leqslant \curlyvee 9\end{array}$ & $\begin{array}{l}99 \\
5.0\end{array}$ & الفكة & 。 \\
\hline$\because$ & $\begin{array}{l}\pi \\
i\end{array}$ & $\begin{array}{c}V Y . \\
r\end{array}$ & $\begin{array}{l}.0 V \\
.7\end{array}$ & $\begin{array}{l}r \Lambda \\
. \wedge\end{array}$ & r. & $\begin{array}{l}r . \\
\vdots\end{array}$ & r. & $\begin{array}{l}v . \\
r\end{array}$ & $\begin{array}{l}\because \because Y \Lambda \\
1 \% . Y V\end{array}$ & v. & $\begin{array}{l}1 \\
\Lambda .7\end{array}$ & $\begin{array}{l}11 \\
. r\end{array}$ & $\begin{array}{l}\because 19 \\
\leqslant r r\end{array}$ & $\begin{array}{l}14 \\
.\end{array}$ & الثير ها & 9 \\
\hline$\ddot{i}$ & $\because$ & $\begin{array}{c}51 . \\
1\end{array}$ & $\begin{array}{l}.0 V \\
.7\end{array}$ & $\begin{array}{l}r 1 \\
.9\end{array}$ & $\begin{array}{l}r . \\
i\end{array}$ & r. & ?. &. & $\begin{array}{l}\because \cdots 1 \varepsilon \\
111.1\end{array}$ & ? & $\begin{array}{l}r \mu \\
V . \Lambda\end{array}$ & $\begin{array}{l}r . \\
.\end{array}$ & $\begin{array}{l}\because \cdot Y r \\
Y T Y\end{array}$ & $\begin{array}{l}1 \leqslant \\
9\end{array}$ & صر & v \\
\hline$i$ & $\begin{array}{l}4 . \\
i\end{array}$ & $\begin{array}{l}14 \\
0.9\end{array}$ & $\begin{array}{l}0 \leqslant \\
.\end{array}$ & $\begin{array}{l}r V \\
. Y\end{array}$ & r. & r. & 9 & 9. & $\begin{array}{l}\because 114 \\
\because 94 \leq\end{array}$ & $\begin{array}{l}1 . \\
.0\end{array}$ & $\begin{array}{l}71 \\
0.9\end{array}$ & $\begin{array}{l}\mu \Lambda \\
. \mu\end{array}$ & $\begin{array}{l}\because .09 \\
9.99\end{array}$ & 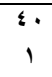 & غريبات & $\wedge$ \\
\hline
\end{tabular}


العـــــــد الثالث والثلاثون

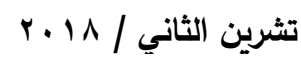

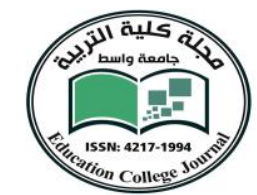

\begin{tabular}{|c|c|c|c|c|c|c|c|c|c|c|c|c|c|c|c|c|}
\hline$\because$ & $\begin{array}{l}1 \% \\
.5\end{array}$ & $\begin{array}{l}Y . \\
1.0\end{array}$ & $\begin{array}{l}0 \leq \\
. \leq\end{array}$ & $\begin{array}{l}r V \\
. r\end{array}$ & r. & $r$ & Y. & $\begin{array}{l}0 . \\
r\end{array}$ & $\begin{array}{l}\because . . P l \\
r \text { rvrr }\end{array}$ & ?. & $\begin{array}{l}17 \\
1.0\end{array}$ & $\begin{array}{l}11 \\
.9\end{array}$ & $\begin{array}{c}\because+1 \leq \\
9 \leq\end{array}$ & 1. & الشكاك & 9 \\
\hline$\because$ & $\begin{array}{l}1 \% \\
.1\end{array}$ & $\begin{array}{l}r . \\
Y\end{array}$ & $\begin{array}{l}0 \leq \\
. \leq\end{array}$ & $\begin{array}{l}r V \\
. r\end{array}$ & $\begin{array}{l}r \\
r\end{array}$ & $\varepsilon$ & $\begin{array}{l}r . \\
\Lambda\end{array}$ & $\begin{array}{l}0 . \\
1\end{array}$ & $\begin{array}{l}\because \text {. r } \\
\varepsilon r O r r\end{array}$ & 9. & $\begin{array}{l}17 \\
7.1\end{array}$ & $\begin{array}{l}17 \\
.4\end{array}$ & $\begin{array}{l}\because \cdot 17 \\
\text { VPr }\end{array}$ & $\begin{array}{l}11 \\
r\end{array}$ & العيلة & 1 \\
\hline 9 & \&. & $\begin{array}{c}0 Y . \\
q\end{array}$ & $\begin{array}{l}.0 Y \\
. \Lambda\end{array}$ & $\begin{array}{l}5 y \\
.8\end{array}$ & r. & r. & 8 & $\begin{array}{l}1 \% \\
.0\end{array}$ & $\begin{array}{l}\because \text {. } 49 \\
\text { ovrq4 }\end{array}$ & 9. & $\begin{array}{l}\leq 0 \\
\ddots \varepsilon\end{array}$ & $\begin{array}{l}19 \\
.9\end{array}$ & $\begin{array}{l}\because .0 Y \\
q q Y\end{array}$ & $\begin{array}{l}r \Lambda \\
\Lambda\end{array}$ & الحليوا & 1 \\
\hline 9 & s. & $\frac{\varepsilon Y}{9}$. & $\begin{array}{l}.0 Y \\
. \Lambda\end{array}$ & $\begin{array}{l}47 \\
.8\end{array}$ & $\begin{array}{l}Y . \\
\varepsilon\end{array}$ & r. & $\begin{array}{l}\varepsilon \\
v\end{array}$ & $\begin{array}{l}18 \\
.9\end{array}$ & $\begin{array}{l}\because * r . \\
\circ Q \circ r V\end{array}$ & $\begin{array}{l}\text { V. } \\
\varepsilon\end{array}$ & $\begin{array}{l}\varepsilon . \\
\wedge .7\end{array}$ & $\begin{array}{l}\text { ro } \\
. r\end{array}$ & $\begin{array}{l}\because \cdot \hat{\cdot} \Lambda \\
r \cdot \Lambda\end{array}$ & $\begin{array}{c}r y \\
r\end{array}$ & السلة & 1 \\
\hline 1. & q. & $\begin{array}{l}Y V \\
\varepsilon . \Lambda\end{array}$ & $\begin{array}{l}\Delta Y \\
. \Lambda\end{array}$ & $\begin{array}{l}47 \\
.8\end{array}$ & i. & r. & $\begin{array}{l}7 . \\
r\end{array}$ & $\begin{array}{l}1 \% \\
. V\end{array}$ & $\begin{array}{l}\because \cdots 11 \\
q \mid r \vee \wedge\end{array}$ & $\begin{array}{l}\varepsilon . \\
1\end{array}$ & $\begin{array}{l}Y \leq \\
9 . \wedge\end{array}$ & $\begin{array}{l}r q \\
. V\end{array}$ & $\begin{array}{l}\because+Y q \\
r Y \leq\end{array}$ & $\begin{array}{c}17 \\
1\end{array}$ & المغيسد & 1 \\
\hline ध & $\begin{array}{l}\text { ro } \\
.5\end{array}$ & $V \leq$ & $\begin{array}{l}\text { Or } \\
. V\end{array}$ & $\begin{array}{l}r y \\
. r\end{array}$ & $\begin{array}{l}r . \\
1\end{array}$ & r. & r. & $\begin{array}{l}1 . \\
.2\end{array}$ & $\begin{array}{l}\because v \leq r \\
.797 V\end{array}$ & $\begin{array}{l}57 \\
.7\end{array}$ & $\begin{array}{l}15 \\
\text { V9 }\end{array}$ & rr & $\begin{array}{l}.107 \\
871\end{array}$ & $\begin{array}{c}\text { No } \\
r\end{array}$ & & 1 \\
\hline
\end{tabular}

المصدر: الباحثة بالاعتماد على نتائج معادلات بيركلي وسنايدر.

التركيز على تصنيف درجات خطورة جريان المياه في الأحواض المائية تبعاً لسرعة وصول المياه الى

مصبات الاحواض من خلال حساب مدة العاصفة والوقت المستغرق لوصول المياه إلى المصب، إذ يدل قصر زمن التركيز على أن الحوض ذو خطورة عالية وبالعكس.

تم الاعتماد على معادلة Snyder(") لحساب زمن التركيز في الأحواض المنتخبة في منطقة الدراسة وهي: - مئ

$\mathrm{Tc}=75 \frac{4(s)^{0.5}+(1.5 l)}{0.8(H)^{0.5}}$

إذ تمثل : n

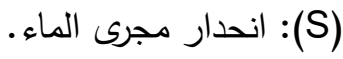

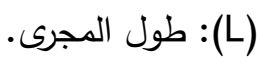

(H): فارق الارتفاع بين المعدل والارتفاع الأدنى للحوض المائي (م).

يعد زمن التركيز من أهم المتغيرات الهيدرولوجية في الحوض المائي كونه ينظر إلى

العاصفة المطرية التي تفوق ديمومتها زمن التركيز على أنها وحدة قادرة على تشكيل جريانات مائية

سطحية داخل الحوض محدثة بذلك سيولاً وفيضانات غزيرة ومدمرة. 
العـــــــد الثالث والثلاثون

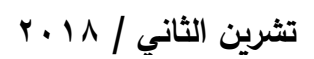

مجلــــة كليـــــة التربيــــة

يعود التباين في زمن التركيز بين الاحواض الى الظروف المناخية وخاصة شدة العواصف

المطرية لاحواض منطقة الدراسة، فضلاً عن بعض خصائص الاحواض التي تعمل على قصر زمن التركيز منها زيادة انحدار مجرى الماء وقصر طول المجرى وقلة فارق الارتفاع بين المعدل والارتفاع الادنى (H) وبالتالي زيادة خطورة الاحواض في المنطقة. إذ تدل قيم مؤشر (TC) المنخفضة الى ارتفاع خطورة الجريان السيلي في تلك الاحواض نتيجة ارتفاع تركز المياه واندفاعها بقوة مسببة سيول جارفة.

يتبين من جدول (1) ان اقل زمن تركيز (TC) بلغ (9.؛ ساعة) وكان من نصيب حوض

الزعفران وهو الزمن المستغرق لوصول المياه من ابعد نقطة في الحوض إلى المصب منذ بداية العاصفة المطرية حتى يصبح الجريان مساوياً لأي زيادة في كمية الأمطار الساقطة. أما اعلى قيم (TC) درجات الخطورة التي يسببها الجريان السيلي للأحواض في منطقة الدراسة مكانياً فيما بينها.

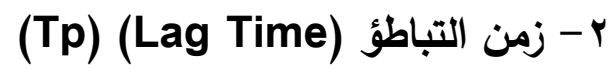

وهو زمن استجابة الأحواض المائية للامطار وصولاً إلى ذروة التصريف، كما يقصد به

الوقت المحصور بين بداية التساقط المطري وبداية الجريان المائي السطحي، ويعد زمن التباطؤ من اهم المعاملات الهيدرولوجية التي تقوم بحساب فاقد التسرب في التربة وتحديد الوقت اللازم لبداية الجريان السطحي بكل حوض، إذ يتأثر بنوع الصخور السطحية والثقوق والفواصل فيها. كما يمكن استخراج زمن التباطؤ من تطبيق المعادلة الآتية:

$\mathrm{Tp}(\mathrm{hr})=\operatorname{ct}($ Lb Lca $) 0.3$

إذ تمثل:

= Lb

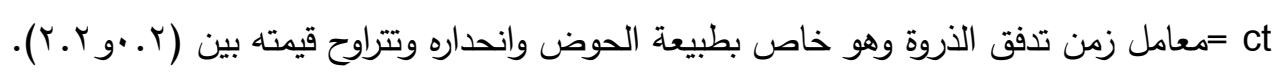

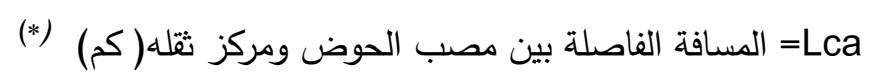


العـــــــد الثالث وإلثلاثون

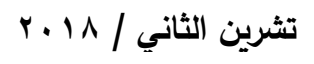

مجلــــة كليـــــة التربيــــة

يرتبط زمن التباطؤ ودرجة الخطورة بعلاقة عكسية، إذ تزداد درجة الخطورة بانخفاض زمن التباطؤ وذلك لانخفاض المدة اللازمة لمياه الامطار لاحداث جريان سطحي، وما يترتب على ذلك من تقلص المياه المتسربة او المتبخرة، وبالتالي زيادة في سرعة وحجم مياه التصريف.

يتضح من جدول (1) ان زمن التباطؤ(Tp) لأحواض المنطقة تراوح ما بين ادنى قيمة

(Y.r) ساعة في حوض الاعمى إلى اعلى قيمة (T.0) ساعة في حوض الفكة نتيجة جريانه فوق

تكوينات جيولوجية حديثة ذات نفاذية عالية ادت إلى زيادة الفاقد بالتسرب والتبخر ، إذ تعتمد قيم (Tp)

على معدلات التسرب في قاع المجرى وانحدار المجرى الطولي وطول المجرى الرئيسي و زيادة نسبة • التبخر

(Tb) - بمن الأساس للسيول

هو المدة الزمنية لامتداد السيل في حوض التصريف من منبعه حتى مصبه، كما تتماثل مع تغيرات زمن التباطؤ ويتم حساب مدة الأساس للسيول (يوم)(days) Time base) بإستخدام المعادلة

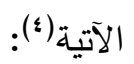

$\mathrm{Tb}($ days $)=3+\frac{t p(h r)}{8}$

$$
\text { (يوم) = Tb (days) }
$$

=Tp

يتضح من بيانات جدول (1) ان زمن الاساس لسيول أحواض المنطقة تراوح بين أقصر مدة أساس لحدوث السيل جاءت بواقع (r.r يوم) في احواض كل من الزعفران والجفته والشكاك والاعمى، في حين كانت أطول مدة ( ^.؟ يوم) في احواض قره تبة والفكة والمغيسل. 
العـــــــد الثالث والثلاثون

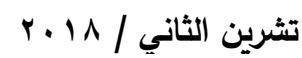

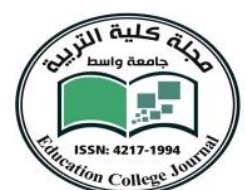

\section{مجلـــة كليـــة التربيــة \\ (V) - سرعة الجريان السيلي}

تعد سرعة الجريان السيلي بمجاري الأودية ذات اهمية كبيرة في تحديد درجة خطورة الجريان

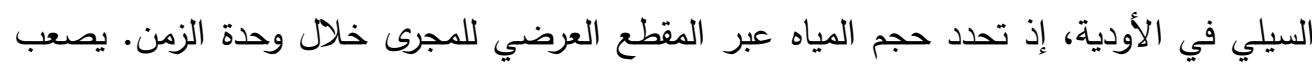
قياس سرعة الجريان في الأنهار والمجاري المائية ميدانياً الا عن طريق رصد حركة الدياه الدياه بالأقمار

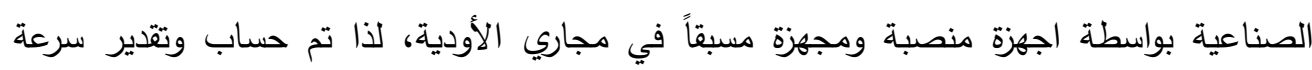
الجريان عن طريق المعادلة الآتية:

\section{$\mathbf{V}=\mathbf{L} / \mathrm{TC}$}

إذ تمثل:

سرعة الجريان V

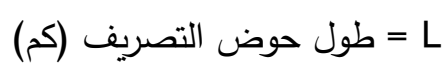

Tc

يظهر من جدول (1) ان اعلى قيم سرعة الجريان السطحي في أحواض منطقة الدراسة

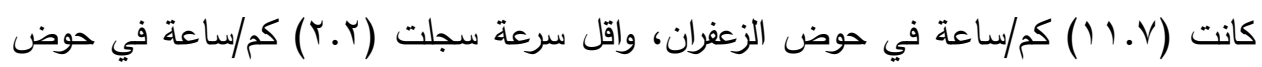

الحليوات، ترتبط سرعة الجريان بعلاقة طردية مع خطورة الجريان السيلي في الحوض.

هـ مدة الارتفاع التدريجي لتدفق السيول

هي المدة اللازمة للارتقاع التدريجي لمياه الامطار في قاع مجاري الأودية بعد حدوث

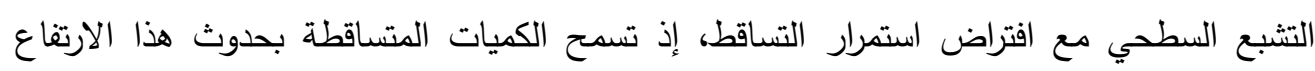

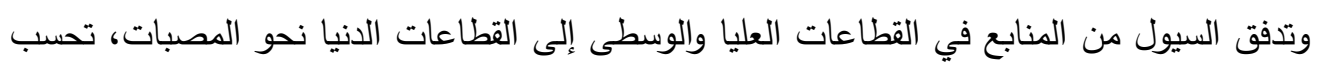
هذه المدة على وفق المعادلة الآتية(•): 
العـــــــد الثالث والثلاثون

مجلـــة كليـــة التربيــة

إذ تمثل : n

Tm فترة الارتفاع التدريجي لتدفق السيل (ساعة). Tb(hr)

يتبين في جدول (1) عند تطبيق المعادلة اعلاه ان اعلى مدة ارتفاع تدريجي سجلت (0. •

ساعة) في حوض قره تبة، اما ادنى مدة فكانت من نصيب حوض الاعمى بواقع (ب.T ساعة).

\section{ج- مدة الانخفاض التدربجي لتدفق السيول(Td)}

وهي المدة الزمنية التي يستغرقها السيل لانخفاض منسوبه رجوع المياه الى وضعها الطبيعي، وتُحسب بتطبيق المعادلة الآتية(`):

$\mathrm{Td}(\mathrm{hr})=\frac{2}{3} \mathrm{~Tb}(\mathrm{hr})$

إذ تمثل: - n - n

Td(hr) Tb(hr)

تتضح نتائج تطبيق المعادلة في جدول(1) ، إذ تراوحت قيم (Td) على مستوى أحواض

المنطقة بين( 9 . • 7 ساعة) في حوض قره تبه وبين (.V. r.V ساعة) في حوض الاعمى، يلاحظ أن زيادة مدة الانخفاض التدريجي لتدفق السيل مرتبطة بزيادة قيم معامل التباطؤ (TC)، إذ توجد علاقة طردية ما بين معامل التباطؤ في الأحواض مع جميع قيم الزمن.

كما إن ارتفاع نتائج قيم الانخفاض التدريجي للسيل، بمعنى طول مدة بقاء المياه الجارية القوية المدمرة يمكن أن تتسبب في حوادث مؤسفة في المناطق السكنية. 
العـــــــد الثالث والثلاثون

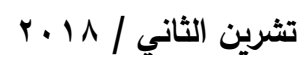

مجلــــة كليـــــة التربيــــة

(Qp) قيمة التدفق الاقصى للسيول - v

تحدد قيمة Qp) أقصى تدفق مائي للسيول يمكنه الوصول إلى مجاري الأودية في حالة

وجود نشاط سيلي قوي، يحسب وفق المعادلة الآتية:

$\mathrm{Qp}=\left(\mathrm{m}^{3} / \mathrm{s}\right)=\frac{C P A}{\operatorname{tp}(\mathrm{hr})}$

إذ تمثل: - n

= كمية التدفق الاقصى للسيول بحوض التصريف (مس/ثا)

A

Tp(hr)

= معامل يرتبط بقابلية حوض التصريف المائي لتخزين المياه، وتتراوح قيمته بين(6.5-2.0)

تتضح نتائج تطبيق المعادلة في جدول(1)، إذ تراوحت قيم (Td) على مستوى أحواض

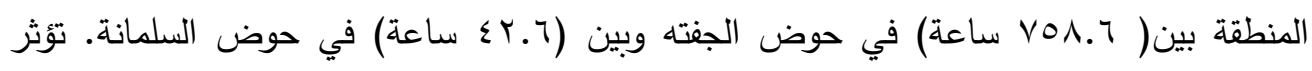
مساحة الحوض في استقبال كمية الأمطار و الجريان السطحي بعلاقة طردية، إذ يزداد الجريان بزيادة المساحة نتيجة امتداد الحوض عبر عدة اقاليم مناخية متتوعة تتغير فيها مواسم الامطار وكمياتها مما يعمل على زيادة كمية الامطار والفائض المائي، ومن جانب أخر صغر مساحة الأحواض قد يعمل على تغطية بعاصفة مطرية واحدة الامر الذي يساهم في سرعة حدوث الجريان المائي وبالتالي زيادة كمية التصريف المائي( (v).

A

معامل يعتمد على عدد المجاري في الوحدة المساحية وتكوينها الجيولوجي ونوع التربة والغطاء النباتي ومساحة الحوض وانحداره ، يحسب وفق المعادلة الاتية: 
العـــــــد الثالث والثلاثون

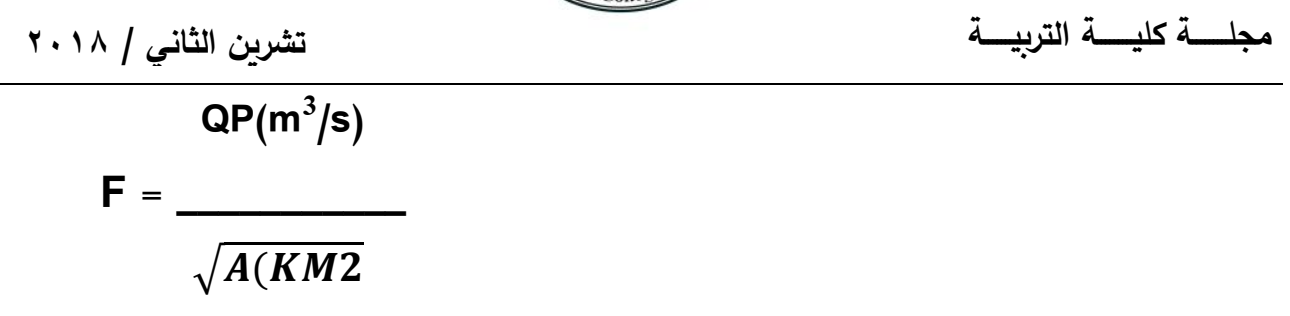

إذ تمثل:

= F

Q التدفق الاقصى للسيل =

P $=A(K M 2$

يظهر من جدول (1) عند تطبيق المعادلة السابقة أن قيم معامل قوة السيل بين احواض

منطقة الدراسة، إذ تراوحت بين (ع مب م/ثا) كأعلى قيمة في حوض الاعمى وادنى قيمة(ع م/ثا) في

حوض قره تبه.

9- المدة الزمنية المثالية لسقوط الأمطار على أحواض التصريف:

هي الوقت الكافي لسقوط الأمطار الذي يتيح للحوض المائي التأهب لجريان مائي بعد

حدوث الفواقد، يرمز لها بالرمز (Tr)، ويمكن استخراجها في أحواض المنطقة بتطبيق المعادلة الآتية

$\operatorname{Tr}(\mathbf{h r})=\frac{t \boldsymbol{p}(\boldsymbol{h r})}{5.5}$

المدة الزمنية المثالية لسقوط الامطار محسوبة (بالساعة) =Tr(hr)

فترة استجابة الحوض المائي لسقوط الامطار محسوبة (بالساعة) =Tp(hr)

يتضح من جدول (1) أن اعلى مدة زمنية لسقوط الأمطار على أحواض المنطقة بلغ (Y.I.

ساعة) في حين جاءت اقل مدة زمنية (ع. • ساعة) في حوضي الاعمى والزعفران، يلاحظ أن المدة 
العـــــــد الثالث والثلاثون

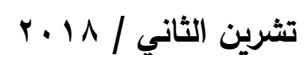

مجلـــة كليــــة التربيـــة

الزمنية المثالية لسقوط الأمطار على أحواض المنطقة تتسم بالانخفاض العام فهي بحدود الساعة الواحدة او اقل في كل الأحواض، كما انها اقل من ازمنة التركيز في كل احواض منطقة الدراسة.

\section{ثالثاً: تصنيف درجات خطورة أحواض تصريف المنطقة:-}

لتحديد درجات خطورة السيول في أحواض المنطقة وتصنيفها تم الاعتماد على الخصائص

الهيدرولوجية السابقة ودمجها والمتضدنة (حجم الجريان R، زمن التركيزTc، زمن التباطؤ Tp، فترة الاساس (اليوم)Tb، سرعة الجريانV، مدة الأرتفاع التدريجي لتدفق السيولTm، مدة الأخفاض

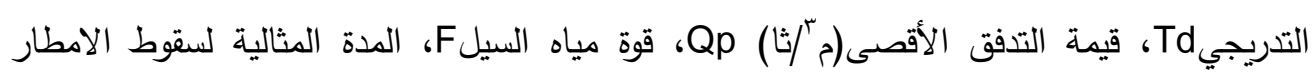

• (Tr T)

واعتماداً على هذه المعايير فانه يمكن حساب خطورة السيول بكل حوض بعدة خطوات:

ا ـ تم تقسيم المتغيرات الهيدرولوجية وبذلك وصل عدد المتغيرات إلى( • () متغيرات.

r. تم تقسيم المتغيرات لكل الأحواض إلى ثلاث مستويات من الخطورة في كل متغير وهي أحواض منخفضة الخطورة، وأحواض متوسطة الخطورة، وأحواض عالية الخطورة، ويحصل الحوض على درجة من درجات الخطورة السابقة في كل متغير ثم تم اسقاطها في الجدول المعد لذلك وبذلك يصبح لدينا (• (1) متغيرات في ثلاث درجات للخطورة ليصبح المجموع (·r) درجة، وتم احتساب معيار الدرجة من ( •r)، ينظر جدول (Y)، وصنفت مستويات الخطورة على اساس هذا المعيار كالاتي:

1. الاحواض التي تقع بين مجموع (1- • ( ) درجة أحواض منخفضة الخطورة. r. الأحواض التي تقع بين مجموع (11 - ـ ب) درجة أحواض متوسطة الخطورة. r. الأحواض التي تقع بين مجموع (اץ-.ب) درجة أحواض عالية الخطورة. ء. تم جمع درجات الخطورة التي حصل عليها كل حوض من كل متغير. 
العـــــــد الثالث والثلاثون

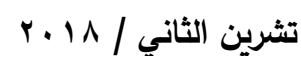

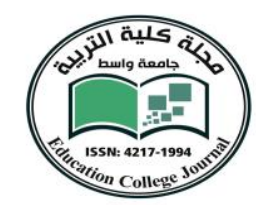

0. قسمت أحواض المنطقة بحسب درجات الخطورة الى المستويات الآتية، كما في خريطة (ب):

• أحواض منخفضة الخطورة: لم تظهر ضمن هذا المستوى أحواض منخفضة الخطورة . أحواض متوسطة الخطورة: تضم ست أحواض وهي حوض قره تبه، وحوض الفكة، وحوض

الاخيصر ، وحوض أبو غريبات، وحوض الحليوات، وحوض السلمانة.

أحواض عالية الخطورة: وتضم معظم أحواض المنطقة وتشمل ثمانية احواض موزعة بين شمال وجنوب وشرق منطقة الدراسة وتشمل (حوض الزعفران، وحوض الجفته (ناشريان)، وحوض

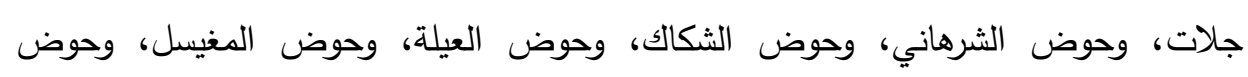

\section{(الاعمى). (1) (n)}

\section{جدول (r)}

تصنيف درجات خطورة السيول في احواض منطقة الدراسة

\begin{tabular}{|c|c|c|c|c|c|c|c|c|c|c|c|c|c|}
\hline التصنيف النهائي & $\mathbf{N}$ & $\mathbf{T r}$ & $\mathbf{F}$ & Qp & Td & Tm & V & $\mathbf{T b}$ & $\mathbf{T p}$ & Tc & $\mathbf{R}$ & اسم الحوض & $ت$ \\
\hline عالي الخطورة & ro & $r$ & $r$ & 1 & 1 & $r$ & $r$ & $r$ & $r$ & $r$ & $r$ & الزعفران & 1 \\
\hline عالي الخطورة & $r \varepsilon$ & $r$ & $r$ & 1 & 1 & r & $r$ & $r$ & $r$ & $r$ & $r$ & 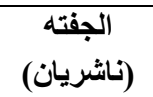 & r \\
\hline متوسط الخطورة & 11 & $r$ & 1 & $r$ & $r$ & $r$ & 1 & 1 & 1 & $r$ & 1 & قره تبه & $r$ \\
\hline عالي الخطورة & ro & $r$ & $r$ & 1 & $r$ & $r$ & $r$ & $r$ & $r$ & $r$ & $r$ & جلات & $\varepsilon$ \\
\hline متوسط الخطورة & 17 & 1 & $r$ & 1 & $r$ & $r$ & 1 & 1 & 1 & 1 & $r$ & الفكة & 0 \\
\hline عالي الخطورة & rr & $r$ & $r$ & $r$ & $r$ & $r$ & 1 & $r$ & $r$ & $r$ & 1 & الثر هاني & 7 \\
\hline متوسط الخطورة & 19 & $r$ & $r$ & $r$ & $r$ & $r$ & 1 & $r$ & $r$ & $r$ & 1 & الاخيصر & V \\
\hline متوسط الخطورة & 11 & 1 & $r$ & 1 & $r$ & $r$ & $r$ & 1 & 1 & $r$ & $r$ & ابو غريبات & $\Lambda$ \\
\hline عالي الخطورة & rr & $r$ & $r$ & 1 & 1 & $r$ & $r$ & $r$ & $r$ & $r$ & 1 & الشكالك & 9 \\
\hline عالي الخطورة & $r \leqslant$ & $r$ & $r$ & 1 & $r$ & $r$ & $r$ & $r$ & $r$ & $r$ & 1 & العيلة & 1. \\
\hline متوسط الخطورة & IV & $r$ & 1 & $r$ & $r$ & $r$ & 1 & $r$ & $r$ & 1 & 1 & الحليوات & 11 \\
\hline متوسط الخطورة & 11 & $r$ & 1 & $r$ & $r$ & $r$ & 1 & $r$ & $r$ & 1 & 1 & السلمانة & ir \\
\hline عالي الخطورة & $r 1$ & $r$ & $r$ & 1 & $r$ & $r$ & 1 & 1 & 1 & 1 & 1 & المغيسل & 14 \\
\hline عالي الخطورة & $r$ & $r$ & $r$ & 1 & 1 & 1 & 1 & $r$ & $r$ & $r$ & $r$ & الاعمى & $1 \varepsilon$ \\
\hline
\end{tabular}

المصدر: الباحثة بالاعتماد على بيانات جدول (1) 


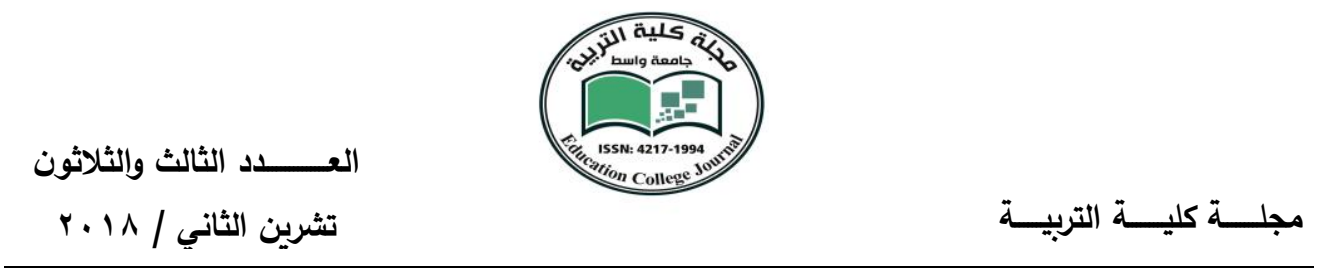

خريطة (r)

تصنيف درجات خطورة السيول في احواض منطقة الدراسة

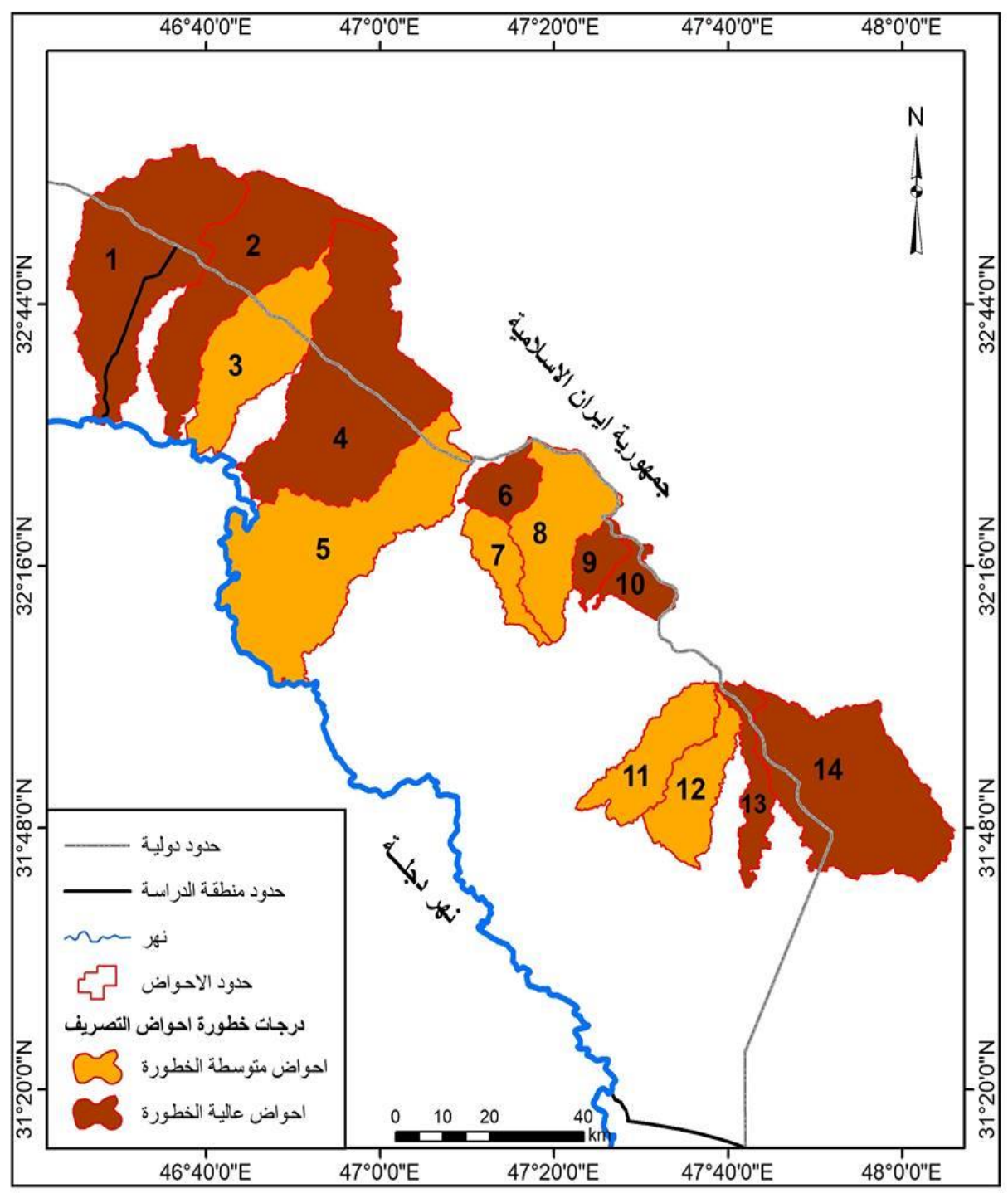

Arc Map المصدر :الباحثة بالاعتماد على بيانات جدول (Y) وباستخدام برنامج 10.4 
العســــــد الثالث وإلثلاثون

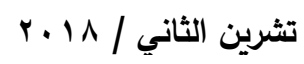

مجلــــة كليـــة التربيــة

الاستنتاجات والتوصيات:

تستنتج الدراسة عدم ظهور أحواض ضمن مستوى منخفضة الخطورة. في حين ظهرت ست

أحواض ضمن مستوى الأحواض متوسطة الخطورة وهي حوض قره تبه، وحوض الفكة، وحوض الاخيصر ، وحوض أبو غربيات، وحوض الحليوات، وحوض السلمانة. اما الاحواض عالية الخطورة فهي ثمانية احواض تشمل (حوض الزعغران، وحوض الجفته (ناشريان)، وحوض جلات، وحوض الثرهاني، وحوض الثكاك، وحوض العيلة، وحوض المغيسل، وحوض الاعمى).

كما توصي الدراسة بضرورة الاهتمام بالتقنيات الحديثة للتنبؤ المبكر للمخاطر ودوره في التخطيط السليم للمشاريع الاقتصادية والتتموية. فضلاً عن انشاء مهارب للمياه لدرء خطر الفيضان كذلك استثمار مياه السيول بمشاريع استراتيجية تخدم المنطقة لاسيما ظروف الجفاف الحالية، وعليه لابد من ايلاء الادارة المائية المبنية على اسس علمية صحيحة دور اساسي وكبير للنهوض بالواقع الاقتصادي محلياً واقليماً.

الهوامش:

(1) (1) جمهورية العراق، وزارة النقل، الهيئة العامة للانواء الجوية والرصد الزلزالي العراقية، بغداد، بيانات (غير

2. https://en.tutiempo.net/climate/iran.html

$$
\text { منشورة)، } 10
$$

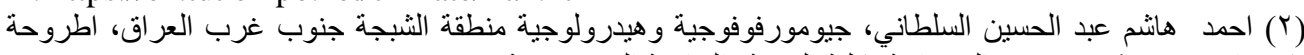

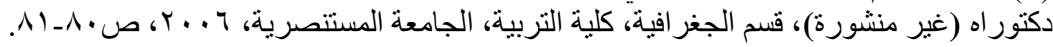

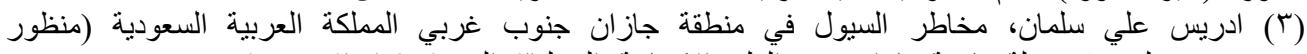

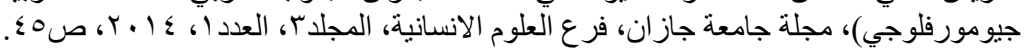

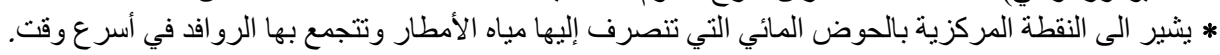

4) H,M, Raghunath, Hydrology ,Principles ,Analysis ,Desigh, NEW AGE INTERNATION (P)LIMITED,2006,p152.

5)Raghunath, Hydrology ,Principles ,Analysis ,Desigh ,op. cit, P 120.

6)Raghunath, H.M, Hydrology Principles Analysis and Design ,John Wiley ,New York ,1984,P164.

( اسحق صالح العكام، العلاقة بين الجريان السطحي و المتغير ات الجيو مورفولوجية لوديان شرق العراق، مجلة الآداب،

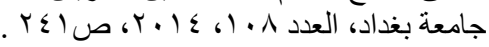

8)Hydrology, iswm, Technical manual, iswm. Nctcog .org/ documents/ technicalmanual/hydrology , 2010, P33. 